Case Report

\title{
Pneumoperitoneum Caused by the Spontaneous Perforation of a Pyometra in an 80-Year-Old Woman: A Case Report
}

\author{
Ki Hoon Kim * \\ Department of Surgery, Inje University Haeundae Paik Hospital, Inje University College of Medicine, Busan, Korea
}

\section{Article history:}

Received: July 11, 2019

Revised: July 12, 2019

Accepted: August 22, 2019

\section{${ }^{*}$ Corresponding Author:}

Ki Hoon Kim

Department of Surgery, Inje University

Haeundae Paik Hospital, Inje University

College of Medicine, Busan, Korea

E-mail: medhun@hanmail.net

\section{ORCID}

Ki Hoon Kim

https://orcid.org/0000-0003-2008-7572

\section{Introduction}

Pyometra is a rare condition which was defined in 1981 as the accumulation of purulent material in the uterine cavity because of an obstruction of the natural drainage of the uterus [1]. The accumulation of pus in the uterine cavity causes a rapid progression of necrosis which may exert pressure on the weakened uterine wall, and lead to spontaneous perforation of the pyometra which may result in spontaneous pneumoperitoneum [2], however, this is rare (0.01-0.05\%) [3]. If a pyometra ruptures, the patient typically develops acute abdominal and generalized peritonitis, increasing the risk of mortality. In this case report, pneumoperitoneum and diffuse peritonitis caused by spontaneously perforated pyometra is described in a patient who was preoperatively diagnosed and successfully treated by emergency laparotomy.

\section{Case Report}

An 80-year-old woman visited the emergency department with a 3-day history of diffuse abdominal pain and nausea. She had a history of hypertension and diabetes for which she had been taking medication for 10 years. Her vital signs were: blood pressure of $110 / 70 \mathrm{mmHg}$, heart rate of 100 beats /minute respiratory rate of 20 breaths/minute, and body temperature of $37.2^{\circ} \mathrm{C}$. On physical examination, her abdomen was slightly distended, with direct tenderness and rebound tenderness of the entire abdomen. A vaginal examination showed no cervical or vaginal anomalies, and there was no vaginal discharge or abnormal fluid in the cavity. Initial laboratory results revealed that her white blood cell count was $20,130 / \mu \mathrm{L}$, C-reactive protein level was $>42 \mathrm{mg} / \mathrm{dL}$, procalcitonin was $>100 \mathrm{ng} / \mathrm{mL}$, and lactic acid level was $4.0 \mathrm{mmol} / \mathrm{L}$. Computed tomography (CT) scans showed the presence of free intra-abdominal air, a fluid-filled uterus with internal air foci, and a focal wall defect at the right anterior aspect of the uterus (Figure 1).

After prompt fluid resuscitation and intravenous antibiotics, an emergency laparotomy was performed to identify the cause of the intra-abdominal free air. (Spontaneous perforation of a pyometra was suspected).

Copious purulent fluid was observed in the peritoneal cavity which was draining from a perforation measuring $2 \mathrm{~cm}$ in diameter in the fundus of the uterus (Figure 2A). 
The uterus exhibited focal necrosis and a perforation in the fundus but showed no evidence of malignancy (Figure 2B). Furthermore, other abdominal organs appeared unremarkable. A total abdominal hysterectomy was performed by a gynecologist. The patient was admitted to the intensive care unit and received intravenous broad-spectrum antibiotics [piperacillin/tazobactam (4.5 g every 6 hours) and metronidazole (500 mg every 8 hours)]. Enterococcus faecalis was isolated from the abdominal pus. Histological examination revealed acute pyogenic inflammation in the uterus involving the cervix, endometrium, myometrium, and parametrium, with perforation and focal necrosis. Although she persisted with a fever which spiked, her condition improved, and she was transferred to the general unit on Postoperative Day 3. Oral food intake was initiated with sips of liquid on Postoperative Day 4 and gradually progressed to a solid diet. On Postoperative Day 10, a follow-up CT scan was performed and revealed no abnormalities. She was transferred to another hospital on Postoperative Day 16 without complications.
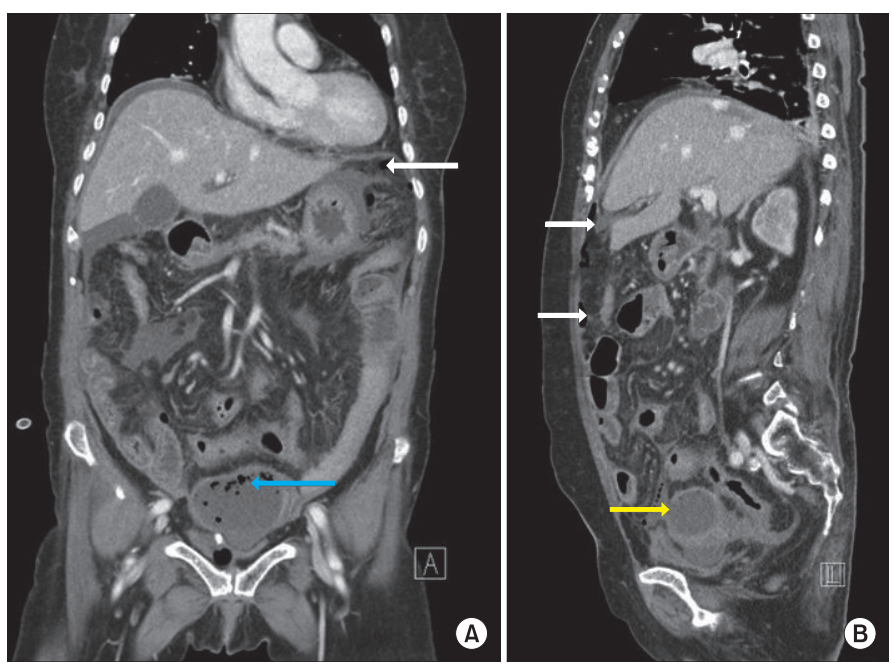

Figure 1. Abdominal computed tomography images. (A) Coronal and (B) sagittal views of abdominal computed tomography scans showing internal air foci in the uterus (blue arrow) and focal wall defect at the uterus (yellow arrow), and free air in the abdomen (white arrow).
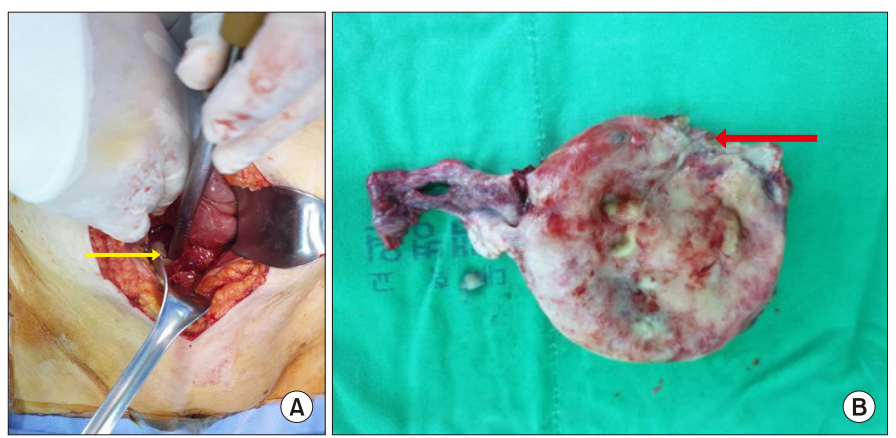

Figure 2. Intraoperative uterine photography. (A) Intraoperative photography showing perforation (yellow arrow) in the fundus of the uterus and (B) postoperative surgical specimen showing defect (red arrow) in the fundus of the uterus.

\section{Discussion}

Pneumoperitoneum is defined as the presence of free air within the peritoneal cavity [4]. In general, more than $90 \%$ of the cases of pneumoperitoneum are caused by gastrointestinal tract perforation [5]. However, pneumoperitoneum may occur without a perforated viscus ("non-surgical" or "spontaneous" or "misleading" pneumoperitoneum).

Spontaneous pneumoperitoneum is associated with intrathoracic, intraabdominal, gynecological, iatrogenic, or other miscellaneous cases (Table 1) [4,5]. Spontaneous pneumoperitoneum in the peritoneal cavity, detected during radiological examination that is not caused by viscus perforation and not requiring surgical intervention, is observed during a laparotomy [5].

Spontaneous pneumoperitoneum that is not due to gastrointestinal perforation and is caused by spontaneous perforation of a pyometra is a condition where there is an

Table 1. Causes of pneumoperitoneum due to non-gastrointestinal tracts $[4,5]$

\begin{tabular}{|c|c|}
\hline & Cause \\
\hline \multirow[t]{6}{*}{ Thoracic } & PEEP ventilation \\
\hline & Pneumothorax/pneumomediastinum \\
\hline & Bronchoscopy \\
\hline & Cardiopulmonary resuscitation \\
\hline & Intrathoracic sepsis \\
\hline & Thoracic trauma/barotrauma \\
\hline \multirow[t]{5}{*}{ Abdominal } & Postoperative: after laparotomy/laparoscopy \\
\hline & PEG tube placement \\
\hline & Pneumatosis cystoides intestinalis \\
\hline & Peritoneal dialysis \\
\hline & Spontaneous bacterial peritonitis \\
\hline \multirow[t]{8}{*}{ Gynecologic } & Vaginal douching \\
\hline & Vaginal insufflation \\
\hline & Post-partum exercise \\
\hline & Knee-chest exercise \\
\hline & Gynecologic examination procedures \\
\hline & Pelvic inflammatory diseases \\
\hline & Coitus \\
\hline & Ovarian cancer \\
\hline \multirow{3}{*}{$\begin{array}{l}\text { Other and } \\
\text { idiopathic }\end{array}$} & Cocaine use \\
\hline & Scleroderma \\
\hline & Aquatic sports, scuba diving \\
\hline
\end{tabular}

PEEP = positive end-expiratory pressure; $P E G=$ percutaneous endoscopic gastrostomy. 
accumulation of pus in the uterine cavity due to an obstruction to the natural drainage of the uterus [1]. A pyometra is reported to occur in $0.1-0.2 \%$ of all gynecology patients, of which $13.6 \%$ are elderly women [6]. The accumulation of purulent material in the uterine cavity with compromised natural drainage, leads to the thinning of the uterine walls, which can cause perforation of the pyometra and spontaneous pneumoperitoneum when under pressure [4]

Pneumoperitoneum due to the perforation of spontaneous pyometra, which is one of the gynecologic causes of these spontaneous pneumoperitoneum, rarely occurs and comprises of $0.01-0.05 \%$ of all cases [3]. The most common presenting symptoms are lower abdominal pain, purulent vaginal discharge, and postmenopausal vaginal bleeding [7]. Symptoms of pyometra may be non-specific; more than $50 \%$ of pyometra cases remain asymptomatic, resulting in a delayed or missed diagnosis [8]. Thus, a definitive diagnosis of pyometra preoperatively is challenging and may, subsequently lead to an increased risk of perforation of the pyometra [7,9]. Once the pyometra has ruptured, the patient develops acute abdominal and generalized peritonitis. These conditions cause an increase in the morbidity and mortality of spontaneously perforated pyometra. Therefore, most cases often require prompt emergency surgical intervention [3]. Septic shock is potentially a life-threatening complication [10]. Management of pyometra depends on the patient's clinical status (emergency or nonemergency) and the status of pyometra (ruptured or unruptured). Urgent cases of ruptured pyometra should be managed by emergency laparotomy, irrigation of peritoneal cavity, hysterectomy, and administration of broad-spectrum antibiotics [11].

In conclusion, although pneumoperitoneum caused by pyometra perforation is considered to be spontaneous peumoperitoneum, delayed diagnosis and treatment may result in an increase in morbidity and mortality. Therefore, aggressive treatment is needed, including surgery, postoperative intensive care support, and administration of antibiotics. If an elderly woman presents with pneumoperitoneum, vague abdominal pain, and gynecological symptoms, acute care surgeons should be mindful of the possibility of pyometra perforation.

\section{Conflicts of Interest}

No potential conflict of interest relevant to this article was reported.

\section{References}

[1] Muram D, Drouin P, Thompson FE, Oxorn H. Pyometra. Can Med Assoc J 1981;125(6):589-92.

[2] Vyas S, Kumar A, Prakash M, Kapoor R, Kumar P, Khandelwal N. Spontaneous perforation of pyometra in a cervical cancer patient: a case report and literature review. Cancer Imaging 2009;9(1):12-4.

[3] Geranpayeh L, Fadaei-Araghi M, Shakiba B. Spontaneous uterine perforation due to pyometra presenting as acute abdomen. Infect Dis Obstet Gynecol 2006;2006:60276.

[4] Mularski RA, Sippel JM, Osborne ML. Pneumoperitoneum: A review of nonsurgical causes. Crit Care Med 2000;28(7):2638-44.

[5] Mularski RA, Ciccolo ML, Rappaport WD. Nonsurgical causes of pneumoperitoneum. West J Med 1999;170(1):41-6.

[6] Inui A, Nitta A, Yamamoto A, Kang SM, Kanehara I, Tanaka H, et al. Generalized peritonitis with pneumoperitoneum caused by the spontaneous perforation of pyometra without malignancy: Report of a case. Surg Today 1999;29(9):935-8.

[7] Yildizhan B, Uyar E, Sișmanoğlu A, Güllüoğlu G, Kavak ZN. Spontaneous perforation of pyometra. Infect Dis Obstet Gynecol 2006;2006:26786.

[8] Nuamah NM, Hamaloglu E, Konan A. Spontaneous uterine perforation due to pyometra presenting as acute abdomen. Int J Gynaecol Obstet 2006;92(2):145-6.

[9] Agarwal R, Suneja A, Sharma A, Vaid NB. An unusual etiology of spontaneous pyometra perforation; a case report. J Reprod Infertil 2011;12(3):235-8.

[10] Abu-Zaid A, Alomar O, Nazer A, Azzam A, Abudan Z, Al-Badawi I. Generalized peritonitis secondary to spontaneous perforation of pyometra in a 63-year-old patient. Case Rep Obstet Gynecol 2013;2013:929407.

[11] Khan A, Prasad J. Perforated pyometra presenting as a pelvic abscess: A case report. Int J Case Rep Imag 2012;3(2):10-4. 